\section{UCDNN}

LIBRARY
University of Connecticut OpenCommons@UConn

EEB Articles

Department of Ecology and Evolutionary Biology

December 2006

\title{
The genetics of sex determination in stinging nettle (Urtica dioica)
}

Robynn K. Shannon

Eastern Connecticut State University

Kent E. Holsinger

University of Connecticut, kent.holsinger@uconn.edu

Follow this and additional works at: https://opencommons.uconn.edu/eeb_articles

\section{Recommended Citation}

Shannon, Robynn K. and Holsinger, Kent E., "The genetics of sex determination in stinging nettle (Urtica dioica)" (2006). EEB Articles. 8.

https://opencommons.uconn.edu/eeb_articles/8 
Robynn K. Shannon* and Kent E. Holsinger

Department of Ecology and Evolutionary Biology

University of Connecticut, U-3043

75 North Eagleville Road

Storrs, CT 06269-3043

The Genetics of Sex Determination in Stinging Nettle (Urtica dioica)

*Current address:

Biology Department, Goddard Hall

Eastern Connecticut State University

83 Windham Street

Willimantic, CT 06226-2295

860-465-4497 (phone)

$860-465-5213$ (fax)

shannonr@easternct.edu 


\begin{abstract}
:
Urtica dioica ("stinging nettle") includes both dioecious and monoecious forms. In most sexually dimorphic angiosperm species, the genetic mechanisms of sex determination are completely unknown. The few species that include both monoecious and dioecious forms provide an unusual opportunity to examine the genetic mechanisms that underlie the separation of sexual functions, through crossing experiments and analysis of progeny segregation. Our focus is on the genetic mechanisms distinguishing monoecious and dioecious forms of $U$. dioica. A complicated picture of sex determination in this species has resulted from crosses between dioecious and monoecious subspecies, as well as between dioecious and monoecious forms of the same subspecies. Most significant is evidence for a maternal influence on sex determination and for the possibility of gynodioecy as an intermediate stage in the evolutionary pathway to dioecy.
\end{abstract}

Key words: sex determination, dioecy, monoecy, cytonuclear sex determination sexual dimorphism 
Introduction:

"The genetic study of sex is important...because...it lies at the root of Mendelian heredity itself and is one of the major factors in evolution" (Muller 1932, p. 135). The known genetic mechanisms underlying sex determination in dimorphic angiosperms are extremely diverse (Ainsworth et al. 1998; Barrett 2002; Dellaporta \& Calderon-Urrea 1993; Grant 1999; Grant et al. 1994; Irish \& Nelson 1989; Lebel-Hardenack \& Grant 1997; Westergaard 1958). In most dimorphic species, however, the mechanisms are completely unknown. The few species that include both monoecious and dioecious forms provide an unusual opportunity to examine the genetic mechanisms that underlie the separation of sexual functions. Analysis of crosses between dioecious forms and those with hermaphroditic flowers necessarily confounds genetic mechanisms responsible for separation of sexual function among flowers with those responsible for separation of sexual function among plants. In contrast, crosses between dioecious and monoecious forms allow us to focus our attention on the genetic mechanisms underlying the separation of sexual functions among plants.

Urtica dioica ("stinging nettle") includes both dioceious (subsp. dioica) and monoecious (subsp. gracilis) forms. Although Richards's 1997 review lists $U$. dioica as having differentiated sex chromosomes, examination of the primary sources does not support this claim (see also Zuk 1970; Woodland et al. 1982). Because so few plant species exhibit both monoecy and dioecy, analysis of crossing data involving these subspecies provides an unusual opportunity for insight into the genetic determinants of sexual dimorphism (Janick \& Stevenson 1955; Westergaard 1958; Lloyd 1975; Wolf et al. 2001; Dorken \& Barrett 2004). Urtica dioica is even more unusual in producing large 
numbers of fertile hybrid progeny. In other species with both monoecious and dioecious forms, crosses often produce too few offspring for genetic analysis (Westergaard 1958; Wolf et al. 2001). In Urtica dioica as in Sagittaria (Dorken \& Barrett 2004), however, a dioecious subspecies is easily crossed with a monoecious subspecies. The hybrids are vigorous and fertile, allowing segregation in a variety of backcross and $F_{1}$ intercrosses to be included in the genetic analyses. In addition, monoecious individuals are occasionally encountered within subsp. dioica, allowing us to determine whether the genetic differences that distinguish monoecious subsp. gracilis from dioecious subsp. dioica are the same as those distinguishing the two sexual forms of subsp. dioica.

Understanding the genetic basis for sex determination is the first step in understanding the evolution of sexual dimorphism, including the intermediate steps that may have occurred along the pathway from hermaphroditism to dioecy. In this paper our focus is on the genetic mechanisms distinguishing monoecious and dioecious forms of $U$. dioica. Specifically, we present evidence that:

- sex determination is under the control of multiple genes.

- maleness and femaleness in subsp. dioica may both have more than one genetic basis.

- the genetic basis of monoecy is different in subsp. gracilis and subsp. dioica.

- monoecious individuals in subsp. dioica are not "inconstant" females, but at least some may be "inconstant" males.

- there is a maternal effect on sex determination.

Methods: 
We performed eight categories of crosses within U. dioica subsp. dioica and between subsp. dioica and subsp. gracilis (Table 1). Because some dioica used in crosses were unisexual and others were monoecious, the sex of the dioica parent(s) (male, female, or monoecious) is specified for each cross (the epithet "dioica," when used alone, refers to subsp. dioica throughout). All gracilis used in crosses were monoecious; unisexual individuals are not known in gracilis. We use the term "reciprocal" to refer to intersubspecific crosses of the same phenotypic gender classes (male, female, and monoecious) that seem to be stably inherited. Many crosses were followed through $F_{2}$ and backcrosses ( $\mathrm{F}_{2}$ and backcross data not presented).

All crosses were conducted in research greenhouses at the University of Connecticut. All parental stocks were tetraploid (presumed autoploid; Woodland et al. 1982), from populations in North America. Woodland and colleagues (1982) found that the more common diploid gracilis was not cross-compatible with any tetraploid members of the genus, including dioica. The results of this study are therefore not affected by ploidy differences among stocks used in crosses, even though most populations of gracilis are diploid. Stocks of dioica were collected in Montreal (Canada) and Montgomery Co., MD (U.S.A.), and stocks of gracilis were collected in Skagit Co., Washington (U.S.A.). No monoecious individuals were observed in either source population of dioica, although they have been documented in other natural populations (de Jong et al. 2005; Glawe \& de Jong 2005; Pollard \& Briggs 1982) and might be found in these two populations on closer examination. Progeny from all crosses were grown to flowering in University of Connecticut greenhouses. 
Because of the minute size of the female flowers and because anthesis occurs as soon as the flowers appear at the apex of the growing shoot (before the inflorescence axis has expanded), bagging of individual flowers or even individual inflorescences was impossible. Urtica dioica is wind pollinated, and the anthers dehisce explosively, sending a small cloud of pollen floating away from the plant each time an anther dehisces. Thus, we performed crosses either by isolating pairs of plants or by bagging pairs of plants to avoid pollen contamination. When bagging plants, entire flowering shoots of the plants to be crossed were enclosed in Nitex ${ }^{\circledR}$ bags with a pore size of $5 \mu \mathrm{m}$, guaranteeing that no pollen (minimum $10 \mu \mathrm{m}$ diameter, Woodland et al. 1982) entered the bags from outside. Typically, male and female flowers are borne at different nodes on monoecious plants, with several successive nodes often producing flowers of the same sex. When a monoecious plant was used as female parent, only nodes with female flowers were bagged, to prevent self-fertilization. If male flowers opened on the female parent while bagged, the cross was discarded. No such precaution was necessary when monoecious plants were used as male parents. Bags were left on the plants two weeks, then the stems were severed from the plant while still in the bags, and the bags were left on the severed stems a few more days. Seeds were allowed to mature on the severed stems about a week longer, then sown directly onto damp ProMix ${ }^{\circledR}$ BX or a mixture of ProMix ${ }^{\circledR} \mathrm{BX}$ and fine vermiculite.

Individual seedlings were potted into 5" pots of ProMix ${ }^{\circledR}$ BX. From October to March, supplemental lighting was used to produce a day length of 15 hours. Scoring was begun as soon as progeny began to flower. Each plant was normally scored three times, recording the sex of flowers produced at each node (male, female, or a mixture). A 
minimum of 10 nodes were scored on most plants, and in most cases the shoot was finished flowering, or nearly so, by the final scoring. With a dioecious species that produces a low frequency of monoecious individuals, one can never be completely certain that an individual scored as male or female will not eventually produce some flowers of the opposite sex; floral meristems have the potential to produce organs of both sexes, remaining bipotent even in unisexual plants (Dellaporta \& Calderon-Urrea 1993; Lebel-Hardenack \& Grant 1997). As a result, our data might slightly under-represent the proportion of monoecious progeny and over-represent the proportion of at least one unisexual class. But even among unisexual plants that were retained for a number of years (for use in crosses) only a few ever produced flowers of the "wrong" sex, and those produced only a tiny percentage of the opposite-sex flowers, a few flowers out of several thousand. Thus, we are confident that very few monoecious individuals could have been missed in our scoring protocol, and only those having such a small proportion of flowers of one sex as to be nearly unisexual would have been missed..

In the case of nodes at which both male and female flowers were produced, a strictly qualitative assessment of gender bias was made. Mixed nodes were therefore recorded as male-biased, female-biased, or unbiased. This made it possible to score each monoecious individual as male-biased, female-biased, or unbiased, based on the total number of male, female, and mixed nodes, as well as the gender bias of the mixed nodes. For example, a plant that had four male nodes, six mixed nodes, two of which were male biased and four of which were female biased, and six female nodes would be scored as female-biased. No attempt was made to take variation in flower number per node into account. Scoring thousands of progeny, each with thousands of flowers, made 
quantitative assessment of gender expression of monoecious individuals, or even of mixed-gender nodes, impractical.

The difficulties in conducting crosses with wind-pollinated plants with minute flowers, coupled with pest management and watering problems, made for considerable variation in the number of progeny produced and grown to maturity per cross. In all cases of low numbers of progeny, whether few maternal families or few progeny within a maternal family, differences in sample size reflected difficulties in setting up the cross and/or culturing the progeny, not differences likely to be due to genetic factors or anything else inherent in the particular cross being performed. Any maternal family with fewer than 10 individuals was excluded from our analyses.

Analyzing sex ratios becomes complicated when more than two sex forms are involved. In dioecious and gynodioecious species, sex ratios may be defined as percentage of either females (Kohn 1989; Korpelainen 2002) or males (Taylor 1999; Glawe \& de Jong 2005). With three sex forms, the relevant ratio depends on the comparison of interest. All three sex forms can be included in the sex ratio, or the sex ratio can be based on any two sex forms (ignoring the third), or the ratio of either males or females to all others might be the most appropriate (McArthur \& Freeman 1982; Quinn \& Engle 1986; Dorken \& Barrett 2004). Sex ratios in our analyses are based on males and females (ignoring monoecious individuals) in some cases and on males, females, and monoecious individuals (hermaphrodites; M:F:H) in others.

Results: 
All crosses were fertile, and in only a few cases (all intersubspecific crosses) did the $F_{1}$ progeny (particularly males) appear to be partially sterile. The results of Cross 7 are based on a single maternal family, and therefore must be interpreted with caution. Within monoecious progeny, there was quantitative variation in the proportions of male and female flowers (data not presented). Crosses between male and female dioica (Cross 1) show that although the primary sex ratio is unbiased (Fig. $1 . a ; \chi_{1}^{2}=0.48$ ), there appears to be considerable sex ratio variation among maternal families; the effect is marginally significant (Fig. $2 ; \chi_{6}^{2}=10.70 ; P<0.10$ ). A small percentage of the progeny were monoecious, and the fraction of monoecious progeny appeared to vary among families as well. The substantial among-family variation suggests that sex determination is influenced by many genes in this species.

Progeny segregation from male and female parents differed according to the origin of the parents. Figure 3 shows the results of a cross in which the male and female parents were the offspring of a selfed monoecious dioica (Fig. 3.a) or in which the male parent was the offspring of a selfed monoecious dioica and the female parent was a dioica $\times$ gracilis hybrid (Fig. 3.b). Although both crosses resulted in a large percentage of monoecious progeny, the ratio of male to female progeny is very different between them, and both progeny ratios are very different from those obtained when male and female parents were themselves the offspring of male and female parents (Cross 1; Fig. 1.a, Fig. 2).

Crosses between female dioica and either monoecious dioica (Cross 3; Fig. 1.c) or gracilis (Cross 5; Fig. 1.e) and between male dioica and either monoecious dioica (Cross 4; Fig. 1.d) or gracilis (Cross 6; Fig. 1.f), provide evidence that the genetic basis 
of monoecy is not the same in the two subspecies. Results from a $2 \times 3$ contingency table analysis indicate that when the unisexual parent was held constant, regardless of whether it was male or female dioica, progeny ratios were very different when the monoecious parent was gracilis from those when the monoecious parent was dioica (Cross $3 \mathrm{M}: \mathrm{F}: \mathrm{H}$ 101:280:210 vs. Cross 5 M:F:H 61:128:34, P=1.189e-08, and Cross 4 M:F:H 15:1:9 vs. Cross $6 \mathrm{M}: \mathrm{F}: \mathrm{H} 33: 231: 34, \mathrm{P}=7.968 \mathrm{e}-14)$, a strong indication that monoecy in gracilis has a different genetic basis from that in dioica.

Results from three pairs of crosses (Table 2; Fig. 1.a-e, g) show that monoecious individuals of $U$. dioica are not inconstant females. In each pair of crosses, the male parent was the same and the female parent was either female dioica or monoecious dioica. In all three pairs, progeny ratios when the female parent was monoecious dioica were strongly male biased and significantly different from progeny ratios when the female parent was female dioica (Cross 1 vs. Cross 4 M:F:H 196:214:62 vs. 15:1:9, $P=6.98 \mathrm{e}-06$; Cross 2 vs. Cross $3 \mathrm{M}: \mathrm{F}: \mathrm{H}$ 90:17:78 vs. 101:280:200, $P=2.2 \mathrm{e}-26$; Cross 5 vs. Cross $7 \mathrm{M}: \mathrm{F}: \mathrm{H}$ 61:121:34 vs. 30:8:20, $P=1.99 \mathrm{e}-09)$, suggesting that sex determination is fundamentally different in female and monoecious dioica.

Results from the comparable pairs of crosses (Table 3, Fig. 1.a-d, f, h), in which the female parent was the same and the male parent was either male dioica or monoecious dioica give a less consistent, but perhaps more interesting, picture of the gender identity of monoecious dioica. When the female parent was female dioica, progeny ratios of monoeious dioica as male parent were strongly female-biased and significantly different from ratios of male dioica as male parent (Cross 1 vs. Cross 3 $\mathrm{M}: \mathrm{F}: H$ 229:214:62 vs. 101:280:210, $P=2.2 \mathrm{e}-16$ ), suggesting that monoecious dioica are 
genetically different from male dioica. Progeny ratios were also female biased when gracilis was the female parent, regardless of whether the male parent was male or monoecious dioicia, with marginally significant greater female bias when the male parent was male dioica (Cross 6 vs. Cross 8 M:F:H 33:231:34 vs. 13:33:6, $P=0.029$ ). In striking contrast, when the female parent was monoecious dioica, progeny ratios were strongly male-biased (especially when considering just males and females) and similar, regardless of whether the male parent was male or monoecious dioica (Cross 2 vs. Cross 4 M:F:H 93:17:78 vs. $15: 1: 9, P=0.6)$. The latter comparison suggests that monoecious dioica are genetically more similar to males than to females. In summary, these crosses provide evidence that monoecious dioica are genetically different from female dioica, but that some monoecious dioica behave as genetic males, at least to some extent. The very small fraction of female progeny $(<10 \%)$ obtained from selfed monoecious dioica (Cross 2 , Fig. 1.b) provides further evidence that some monoecious individuals are best interpreted as inconstant males.

One final comparison that sheds light on the gender of monoecious individuals is that of Crosses 3 and 4, between unisexual and monoecious dioica (Fig. 1.c, d). Not only are progeny ratios significantly different between male and female dioica as the unisexual parent, but in each case the ratio bias is in the direction of the sex of the unisexual parent. In other words, female crossed with monoecious yielded female-biased progeny and male crossed with monoecious yielded male-biased progeny (Cross 3 vs. Cross 4 M:F:H 101:280:200 vs. $15: 1: 9, P=8.4 \mathrm{e}-08)$. This comparison argues for monoecious individuals being neither inconstant males nor inconstant females, but rather a genetically distinct gender class. 
Finally, several of our results demonstrate a maternal (presumably cytoplasmic) influence on sex determination. Not only did we find an excess of female progeny in many crosses, we also found that progeny ratios differed between reciprocal crosses. We found significant female biases in the progeny of crosses of female with monoecious dioica (Fig. 1.c), of gracilis with both male and female dioica (Fig. 1.e, f), and of gracilis with monoecious dioica (as male parent) (Fig. 1.h). Similarly, reciprocal crosses between gracilis and monoecious dioica yielded asymmetrical progeny segregation, strongly male biased in one cross and strongly female biased in the other (Crosses 7 and 8, Fig. 1.g, h; Cross 7 M:F 31:8; Cross 8 M:F 13:33 - Fisher's exact test: $\mathrm{P}=3.2 \mathrm{e}-6)$.

Discussion:

In his pioneering research on Urtica dioica genetics, Zuk (1970) concluded that this species has a "rather primitive" mechanism of sex determination, with sexdetermining loci distributed over several chromosomes. Of his crossing results between hermaphrodites and between males or females and hermaphrodites he reported, "In the progeny...no regularity is found in the segregation of sex-determining factors, the proportion of $\hat{O}$ and $q$ plants being quite fortuitous." As with Zuk's results, the complex inheritance pattern revealed in our crosses precludes construction of a simple genetic model for sex determination in Urtica dioica. Nevertheless, several important insights emerge from these results. First, more than one gene is involved in sex determination in this species. We cannot suggest how many, but the results are not consistent with singlelocus sex determination, such as that found by Wolf (2001) for Datisca, under which 1:1 sex ratios from all crosses would be expected. Moreover, progeny sex ratios differ 
among maternal families when crossing male and female dioica (Fig. 2, $P<0.10$ ), suggesting that genetic variation among maternal lines influences progeny sex ratios. De Jong and colleagues (de Jong \& Klinkhamer 2002; de Jong et al. 2005) have obtained similar results. More maternal families need to be tested to determine whether the observed variation is continuous.

Second, there are apparently several different genetic mechanisms for producing males and females, as suggested by different progeny segregations from male and female parents of different ancestry. Such different progeny segregations also provide further evidence that sex determination in this species is under the control of multiple genes. Male and female dioica yielded different progeny segregations when crossed, depending on whether they were the offspring of male and female parents (Fig. 1.a) or of a selfed hermaphrodite parent (Fig. 3.a). A male dioica (from male and female parents) crossed with a female dioica-gracilis hybrid produced still a different progeny segregation (Fig. 3.b).

Third, monoecy in subsp. dioica clearly has a different genetic basis than monoecy in subsp. gracilis, a surprising result, given that they are so closely related. Monoecy is thought to be the ancestral condition in most lineages in which both monoecy and dioecy occur (Renner \& Ricklefs 1995; Webb 1999). If dioecy evolved from monoecy in $U$. dioica, as expected, the genetic basis of monoecy in dioica would be expected to resemble that in gracilis, as both would reflect the ancestral (monoecious) condition. The different progeny ratios obtained from gracilis and monoecious dioica in otherwise equivalent crosses indicates a different genetic basis for monoecy in the two subspecies. 
Fourth, the occasional monoecious individuals found in natural populations of dioica do not represent inconstant females (sensu Lloyd 1980), but some appear to represent inconstant males. When female and monoecious dioica were crossed with gracilis (as the male parent, Crosses 5 and 7), the progeny sex ratios are very different (Fig. 1.e, g), indicating that monoecious dioica are genetically different in their sex determination from female dioica (i.e., monoecious individuals are not simply females that are producing some flowers of the "wrong" sex).

In contrast, we found conflicting results on the question of whether monoecious dioica represent inconstant males. In some crosses, monoecious dioica behaved like males, or at least more similarly to males than to females, as can be seen in a comparison of Crosses 2 and 4 (Fig. 1.b, d; Table 3) and in the small fraction of female progeny from selfed female dioica in Cross 2 (Fig. 1.b). These results indicate that some monoecious individuals of subsp. dioica may represent inconstant males, consistent with the findings of de Jong and colleagues (2005), based on the direction of labile sex expression in greenhouse experiments. Pollard's (1981) limited sample of 20 progeny from two maternal families of selfed monoecious dioica showed a male bias in both families, with nearly equal proportions of female and monoecious progeny.

Other results, however, contradict the interpretation of monoecious dioica as inconstant males. Comparisons of Crosses 1 and 3 (Fig. 1.a, c; Table 3) and Crosses 3 and 4 (Fig. 1.c, d) indicate that monoecious dioica are distinctly different from males. The question of whether or not monoecious dioica represent inconstant males has important implications for the evolution of dioecy in this species, due to different theoretical expectations for the paradioecy vs. the gynodioecy pathway. The paradioecy 
pathway predicts a series of mutations reallocating male and female function in monoecious individuals, in which case monoecious individuals would be equally likely to be males or females, whereas the gynodioecy pathway predicts inconstant males only (Lloyd 1980; Charlesworth \& Guttman 1999; Dorken \& Barrett 2004). It is possible that there are two genetically different types of monoecious individuals in $U$. dioica, those that are inconstant males (de Jong et al. 2005), as in Sagittaria (Dorken \& Barrett 2004), and those that are genetically distinct in their sex determination from either males or females.

Finally, several of our results indicate a maternal (presumably cytoplasmic) influence on sex determination, although further crosses would be necessary to test the hypothesis of cytonuclear sex determination. When individuals with cytonuclear sex determination are crossed with individuals from another taxon, or even another population, and the cytoplasmic male sterility factors are decoupled from their restorers, two common types of progeny segregation occur: non-Mendelian ratios, particularly an excess of female progeny (Frankel \& Galun 1977; Couvet et al. 1986; Belhassen et al. 1991) and asymmetrical progeny ratios in reciprocal crosses (Grun 1976; Kheyr-Pour 1980, 1981; Kaul 1988; Belhassen et al. 1991). Our results include examples of both, suggestive of a cytonuclear model of sex determination. While not all maternal effects on sex determination indicate a cytoplasmic basis for sex determination (Fishman \& Willis 2006), the data presented here are consistent with predictions based on both theoretical and empirical results (Grun 1976; Frankel \& Galun 1977; Kheyr-Pour 1980, 1981; Kaul 1988; Belhassen et al. 1991; Maurice et al. 1993; Maurice et al. 1994). In particular, our results are not consistent with the two-locus nuclear model that Dorken 
and Barrett (2004) used to explain sex determination in Sagittaria. Evidence presented above that at least some monoecious individuals are inconstant males but never inconstant females suggests that females are male-sterile and that the cytoplasmic influence is therefore in the direction of female bias.

When we crossed gracilis with unisexual dioica, the progeny were strongly female biased, regardless of the direction of the cross (Crosses 5 and 6; Fig. 1.e, f). Two other crosses ( 3 and 8$)$ also yielded significant female biases in the $F_{1}$ (Fig. 1.c, h). Female dioica parents produced female-biased progeny when crossed with a monoecious individual, whether that individual was dioica or gracilis (Crosses 3 and 5; Fig. 1.c, e). Several of the male and monoecious $\mathrm{F}_{2}$ and backcross progeny from Cross 2 had small male flower buds that never opened and appeared to be sterile (data not presented). There is, therefore, evidence for a maternal influence in the direction of male sterility in U. dioica, although we cannot be certain that it arose prior to the evolution of dioecy.

Similarly, asymmetrical segregation in reciprocal crosses, such as Crosses 7 and 8 (Fig. 1.g, h), is critical for distinguishing between nuclear and cytonuclear sex determination (Kheyr-Pour 1980, 1981; Belhassen et al. 1991). Cross 7 resulted in strongly male-biased progeny and Cross 8 in strongly female-biased progeny, although these results must be interpreted with caution because Cross 7 results were based on a single maternal family. When male sterility is determined solely by nuclear genes, no differences between reciprocal crosses is expected (Grun 1976). The significant differences in progeny segregation between crosses indicates non-Mendelian heritance, and that the monoecious parents do not have the same cytoplasmic genes (Belhassen et al. 1991). 
Our results have implications for the possible intermediate evolutionary stages between monoecy and dioecy in U. dioica. Webb (1999) reviewed two cases where dioecy appears to have evolved from monoecy via gynodioecy, but dioecy in lineages in which monoecy also occurs is generally assumed to have evolved via the "paradioecy" pathway (Lloyd 1980; Renner \& Ricklefs 1995). Although the finding of multigenic control of sex determination is consistent with the paradioecy pathway, two other results from our study are not: differences in the genetic basis of monoecy in the two subspecies and possible inconstant males but no inconstant females. The finding of a maternal influence in sex determination is consistent with the gynodioecy pathway, as is the finding of female constancy (Charlesworth \& Charlesworth 1978; Lloyd 1980). Clearly, evolutionary pathways cannot be inferred solely from presumed ancestral states. Based on our results, the gynodioecy pathway appears to have been a more likely route to dioecy than the paradioecy pathway in this species (Charlesworth \& Charlesworth 1978; Lloyd 1980; Dorken \& Barrett 2004). Although gynodioecy has been associated with the evolution of dioecy from monoecy in a few species (Webb 1999; Sarkissian et al. 2001; Dorken \& Barrett 2004), cytonuclear sex determination has not previously been associated with species in which monoecy occurs. In U. dioica, dioecy may have evolved through an intermediate stage of cytoplasmically determined gynodioecy. Dorken and Barrett (2004) presented evidence that dioecy evolved from monoecy via gynodioecy in Sagittaria latifolia, but their results were consistent with purely nuclear sex determination. The genetic basis of sex determination in $U$. dioica and other species in which a monoecy-gynodioecy-dioecy pathway appears to have been likely should continue to be a fruitful area of research. 
Acknowledgements

This research was supported by a Ronald Bamford Endowment grant and a Henry N. Andrews Endowment grant from the Department of Ecology and Evolutionary Biology, and a Dissertation Fellowship from the American Association of University Women Educational Foundation. C. Morse, S. Olsen, and M. Johnson provided greenhouse support and assistance. D. Woodland and J. Galusha made this research possible by providing most of the stocks used in the initial crosses. S. G. Weller, D. Charlesworth, C. Schlichting, D. Les, G. Anderson, J. Silander, and anonymous reviewers made comments that led to substantial improvements in this paper..

\section{References}

Ainsworth C, Parker J, Buchanan-Wollaston V (1998) Sex determination in plants. Curr. Top. Dev. Biol. 38:167-223

Barrett SCH (2002) The evolution of plant sexual diversity. Nature Reviews Genetics

\section{$3: 274-284$}

Belhassen E, Dommée B, Atlan A, Gouyon PH, Pomente D, Assouad MW, Couvet D (1991) Complex determination of male sterility in Thymus vulgaris L.: genetic and molecular analysis. Theor Appl Genet 82:137-143

Charlesworth D, Charlesworth B (1978) Population genetics of partial male-sterility and the evolution of monoecy and dioecy. Heredity 41:137-153

Charlesworth D, Guttman DS (1999) The evolution of dioecy and plant sex chromosome systems. In: Ainsworth CC (ed) Sex Determination in Plants. BIOS Scientific Publishers, Oxford, pp 25-49 
Couvet D, Bonnemaison F, Gouyon P-H (1986) The maintenance of females among hermaphrodites: the importance of nuclear-cytoplasmic interactions. Heredity $57: 325-330$

de Jong TJ, Klinkhamer PGL (2002) Sex ratios in dioecious plants. In: Hardy ICW (ed) Sex Ratios: Concepts and Research Methods. Cambridge Univ. Press, New York, pp 349-364

de Jong TJ, Nell HW, Glawe GA (2005) Heritable variation in seed sex ratio of the stinging nettle (Urtica dioica). Plant Biol (Stuttg) 7:190-194

Dellaporta S, Calderon-Urrea A (1993) Sex determination in flowering plants. The Plant Cell 5:1241-1251

Dorken ME, Barrett SC (2004) Sex determination and the evolution of dioecy from monoecy in Sagittaria latifolia (Alismataceae). Proc R Soc B 271:213-219

Fishman L, Willis JH (2006) A cytonuclear incompatibility causes anther sterility in Mimulus hybrids. Evolution 60:1372-1381

Frankel R, Galun E (1977) Pollination Mechanisms, Reproduction, and Plant Breeding. Springer, Berlin

Glawe GA, de Jong TJ (2005) Environmental conditions affect sex expression in monoecious, but not in male and female plants of Urtica dioica. Sex Plant Reprod 17:253-260

Grant SR (1999) Genetics of gender dimorphism in higher plants. In: Geber MA, Dawson TE, Delph LF (eds) Gender and Sexual Dimorphism in Flowering Plants. Springer, Berlin, pp 247-274 
Grant S, Houben A, Vyskot B, Siroky J, Pan W-H, Macas J, Saedler H (1994) Genetics of sex determination in flowering plants. Developmental Genetics 15:214-230

Grun P (1976) Cytoplasmic Genetics and Evolution. Columbia Univ Press, New York

Irish EE, Nelson T (1989) Sex determination in monoecious and dioecious plants. Plant Cell 1:737-744

Janick J, Stevenson EC (1955) Genetics of the monoecious character in spinach. Genetics 40:429-437

Kaul MLH (1988) Male Sterility in Higher Plants. Monogr Theor Appl Genet, Vol 10. Springer, Berlin

Kheyr-Pour A (1980) Nucleo-cytoplasmic polymorphism for male sterility in Origanum vulgare $\mathrm{L}$. J Hered 71:253-260

_ (1981) Wide nucleo-cytoplasmic polymorphism for male sterility in Origanum vulgare L. J Hered 72:45-51

Kohn JR (1989) Sex ratio, seed production, biomass allocation, and the cost of male function in Cucurbita foetidissima HBK (Cucurbitaceae). Evolution 43:14241434

Korpelainen H (2002) A genetic method to resolve gender complements investigations on sex ratios in Rumex acetosa. Molec Ecol 11:2151-2156

Lebel-Hardenack S, Grant SR (1997) Genetics of sex determination in flowering plants. Trends Plant Sci 2:130-136

Lloyd DG (1975) Breeding systems in Cotula. III. Dioecious populations. New Phytol 74:109-123 
(1980) The distributions of gender in four angiosperm species illustrating two evolutionary pathways to dioecy. Evolution 34:123-134

Maurice S, Charlesworth D, Desfeux C, Couvet D, Gouyon P-H (1993) The evolution of gender in hermaphrodites of gynodioecious populations with nucleo-cytoplasmic male-sterility. Proc R Soc B 251:253-261

Maurice S, Belhassen E, Couvet D, Gouyon P-H (1994) Evolution of dioecy: can nuclear-cytoplasmic interactions select for maleness? Heredity 73:346-354

McArthur ED, Freeman DC (1982) Sex expression in Atriplex canescens: Genetics and environment. Bot Gaz 143:476-482

Muller H J (1932) Some genetic aspects of sex. Am Nat 66:118-138

Pollard AJ (1981) Genecological studies of Urtica dioica L. Ph.D. Diss., Univ. Cambridge, Cambridge.

Pollard AJ, Briggs D (1982) Genecological studies of Urtica dioica L. I. The nature of intraspecific variation in U. dioica. New Phytol 92:453-470

Quinn JA, Engel JL (1986) Life-history strategies and sex ratios for a cultivar and a wild population of Buchloe dactyloides (Gramineae). Am J Bot 73:874-881

Renner SS, Ricklefs RE (1995) Dioecy and its correlates in the flowering plants. Am J Bot 82:596-606

Richards, AJ (1997) Plant Breeding Systems (second edition). Chapman \& Hall, London Sarkissian TS, Barrett SCH, Harder LD (2001) Gender variation in Sagittaria latifolia (Alismataceae): Is size all that matters? Ecol 82: 360-373

Schultz ST (1994) Nucleo-cytoplasmic male sterility and alternative routes to dioecy. Evolution 48:1933-1945 
Taylor DR (1999) Genetics of sex ratio variation among natural populations of a dioecious plant. Evolution 53:55-62

Webb CJ (1999) Empirical studies: Evolution and maintenance of dimorphic breeding systems. In: Geber MA, Dawson TE, Delph LF (eds) Gender and Sexual Dimorphism in Flowering Plants. Springer, Berlin, pp 61-96

Weller SG, Sakai AK (1991) The genetic basis of male sterility in Schiedea (Caryophyllaceae), an endemic Hawaiian genus. Heredity 67:265-273

Westergaard M (1958) The mechanism of sex determination in dioecious flowering plants. Adv Genet 9:217-281

Wolf DE, Satkoski JA, White K, Rieseberg LH (2001) Sex determination in the androdioecious plant Datisca glomerata and its dioecious sister species $D$. cannabina. Genetics 159:1243-1257

Woodland DW, Bassett IJ, Crompton C, Forget S (1982) Biosystematics of the perennial North American taxa of Urtica. I. Chromosome number, hybridization, and palynology. Syst Bot 7:269-281

Zuk J (1970) Structure and function of sex chromosomes in Rumex thyrsiflorus. Acta Societatis Botanicorum Poloniae 39:539-564 
Figure 1. Percentage of $\hat{\partial}, q$, and monoecious progeny from the eight types of crosses (see Table I). Note scale differences in Y-axes. $P$ values are for $\chi^{2}$ tests on $\delta^{\lambda}$ and $P$ progeny. a. U. dioica subsp. dioica $q \times \widehat{\oint}($ Cross 1$) . \mathrm{N}=505$, seven maternal families, $P=0.48$. b. Selfed monoecious $U$. dioica subsp. dioica (Cross 2). N=188, two maternal families, $P<0.0001$. c. $\$ \times$ monoecious $U$. dioica subsp. dioica (Cross 3$) . \mathrm{N}=595$, eleven maternal families, $P<0.0001$. d. Monoecious $\times$ ô U. dioica subsp. dioica (Cross 4). $\mathrm{N}=37$, four maternal families, $P<0.0001$. e. ㅇ $U$. dioica subsp. dioica $\times$ subsp. gracilis (monoecious) (Cross 5). $\mathrm{N}=238$, six maternal families, $P<0.0001$. f. U. dioica

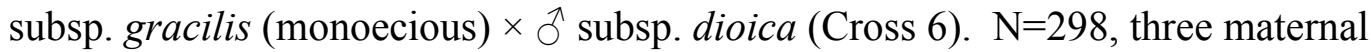
families, $P<0.0001$. g. Monoecious $U$. dioica subsp. dioica (as maternal parent) $\times$ subsp. gracilis (monoecious) (Cross 7). $\mathrm{N}=58$, one maternal family, $P=0.0002$. h. U. dioica subsp. gracilis (monoecious, as maternal parent) $\times$ monoecious subsp. dioica (Cross 8 ). $\mathrm{N}=52$, four maternal families, $P=0.003$.

Figure 2. Progeny ratios from Cross 1 (Fig. 1.a) broken down by maternal family, number of progeny in parentheses. Error bars indicate standard error.

Figure 3. Percentage of $\hat{\partial}, \phi$, and monoecious progeny from crosses between male and female parents of different origins. $P$ values are for $\chi^{2}$ tests on $\delta^{\lambda}$ and $q$ progeny. a. $U$. dioica subsp. dioica $q \times \widehat{O}\left(\operatorname{Cross} 2 \mathrm{~F}_{2}\right) . \mathrm{N}=151$, five maternal families, $P<0.001$. b. $U$. dioica subsp. dioica $q \times \widehat{O}$. $\widehat{O}$ parent from Cross $2 \mathrm{~F}_{1}$, $q$ parent from Cross $6 \mathrm{~F}_{1} . \mathrm{N}=48$, one maternal family. $P=0.4$. 
Table 1. The eight categories of crosses conducted using plants of Urtica dioica subsp.

dioica and $U$. dioica subsp. gracilis. (All plants of subsp. gracilis were monoecious; some plants of subsp. dioica were unisexual, others were monoecious, as indicated.)

\begin{tabular}{|c|c|c|}
\hline cross number & female parent & male parent \\
\hline 1 & q dioica & ó dioica \\
\hline 2 & $\begin{array}{l}\text { monoecious } \\
\text { dioica }\end{array}$ & monoecious dioica \\
\hline 3 & 9 dioica & monoecious dioica \\
\hline 4 & $\begin{array}{l}\text { monoecious } \\
\text { dioica }\end{array}$ & $\hat{o}$ dioica \\
\hline 5 & 9 dioica & gracilis \\
\hline 6 & gracilis & o dioica \\
\hline 7 & $\begin{array}{l}\text { monoecious } \\
\text { dioica }\end{array}$ & gracilis \\
\hline 8 & gracilis & monoecious dioica \\
\hline
\end{tabular}


Table 2. Are monoecious dioica genetically female-like? $P$ values are from $2 \times 3$ contingency tests comparing $\mathrm{M}: \mathrm{F}: \mathrm{H}$ progeny ratios.

\begin{tabular}{|c|c|c|c|c|}
\hline \multirow[t]{2}{*}{ Male Parent } & \multicolumn{3}{|c|}{ Female Parent } & \\
\hline & Female dioica & & Monoecious dioica & \\
\hline Male dioica & Cross 1 & vs. & Cross 4 & $P=7.0 \mathrm{e}-06$ \\
\hline Monoecious dioica & Cross 3 & vs. & Cross 2 & $P=2.2 \mathrm{e}-26$ \\
\hline gracilis (monoecious) & Cross 5 & vs. & Cross 7 & $P=2.0 \mathrm{e}-09$ \\
\hline
\end{tabular}

Table 3. Are monoecious dioica genetically male-like? $P$ values are from $2 \times 3$ contingency tests comparing M:F:H progeny ratios.

Female Parent

\begin{tabular}{ccccc}
\hline & \multicolumn{3}{c}{ Male Parent } \\
\cline { 2 - 2 } Male dioica & & \multicolumn{2}{c}{ Monoecious dioica } & \\
\cline { 2 - 2 } Female dioica & Cross 1 & vs. & Cross 3 & $P=2.2 \mathrm{e}-16$ \\
Monoecious dioica & Cross 4 & vs. & Cross 2 & $P=0.6$ (both male biased) \\
gracilis (monoecious) & Cross 6 & vs. & Cross 8 & $P=0.03$ (both female biased)
\end{tabular}


Results from all crosses. Number of progeny in each family given in parentheses. Monoecious progeny are divided into male biased/female biased/unbiased. $\chi^{2}{ }_{\text {het }}$ tests the null hypothesis that progeny proportions are equal across maternal families. Statistics in the "females" column refer to a heterogeneity test of male:female proportions. Statistics in the "monoecious" column refer to a heterogeneity test of (male+female):monoecious proportions. $\chi_{1: 1}^{2}$ tests the null hypothesis that the males and females occur in equal proportions in progeny. We report it only for $\mathrm{F}_{1}$ crosses, because expectations for backcrosses are not clear in the absence of a genetic model. $\left({ }^{+} \mathrm{P}<0.10 ; * \mathrm{P}<0.05 ;{ }^{\mathrm{a}} \mathrm{P}<\right.$ $\left.0.01 ;{ }^{\mathrm{b}} \mathrm{P}<10^{-4}\right)$

\section{Maternal Family (n) males females monoecious}

\section{Cross 1:}

\begin{tabular}{ccccc}
$9 \times \hat{\text { dioica }}$ & & & & \\
\hline $\mathrm{F}_{1}$ & $2510(93)$ & 51 & 37 & $4 / 1 / 0$ \\
& $2511(74)$ & 30 & 29 & $5 / 9 / 1$ \\
& $2512(78)$ & 38 & 28 & $4 / 8 / 0$ \\
$2513(83)$ & 35 & 43 & $2 / 3 / 0$ \\
& $2514(58)$ & 35 & $21^{+}$ & $1 / 1 / 0$ \\
& $2515(32)$ & 14 & 16 & $1 / 1 / 0$ \\
$2516(87)$ & 26 & 40 & $10 / 9 / 2$ \\
& $\chi_{\text {het }}^{2}$ & & $10.68^{+}$ & $28.9^{\mathrm{b}}$ \\
& $\chi^{2}$ & & 0.51 & \\
\hline
\end{tabular}

Cross 2:

selfed monoecious dioica

\begin{tabular}{ccccc} 
Selfed monoecious dioica & $2499(89)$ & 53 & 3 & $16 / 4 / 13$ \\
\hline $\mathrm{F}_{1}$ & $2518(99)$ & 40 & 14 & $17 / 19 / 9$ \\
& $\chi_{\text {het }}^{2}$ & & $8.90^{\mathrm{a}}$ & 1.35 \\
& $\chi_{1: 1}^{2}$ & & $52.5^{\mathrm{b}}$ & \\
\hline
\end{tabular}

Cross 3:

\begin{tabular}{ccccc} 
o $\times$ monoecious dioica & \\
\hline $\mathrm{F}_{1}$ & $310(32)$ & 17 & 15 & 0 \\
& $139(17)$ & 5 & 9 & $3 / 0 / 0$ \\
& $142(15)$ & 4 & 7 & $2 / 2 / 0$ \\
& $145(13)$ & 6 & 4 & $0 / 2 / 1$ \\
$195 / 205(114)$ & 17 & 52 & $28 / 12 / 5$ \\
& $201(42)$ & 9 & 18 & $9 / 4 / 2$ \\
& $202(96)$ & 12 & 47 & $28 / 7 / 2$ \\
& $203(130)$ & 26 & 66 & $27 / 8 / 3$ \\
& $204(20)$ & 5 & 9 & $4 / 2 / 0$ \\
& $207(102)$ & 0 & 53 & $11 / 21 / 17$ \\
& $\chi_{\text {het }}^{2}$ & & $40.3^{\mathrm{b}}$ & $36.3^{\mathrm{b}}$ \\
$\chi_{\text {(1:1 }}^{2}$ & & $84.1^{\mathrm{b}}$ & \\
\hline
\end{tabular}

Cross 4:

\begin{tabular}{ccccc} 
monoecious $\times$ dioica & \\
\hline $\mathrm{F}_{1}$ & $144(15)$ & 11 & 0 & $4 / 0 / 0$ \\
& $246(10)$ & 4 & 1 & $2 / 3 / 0$ \\
& $\chi_{\text {het }}^{2}$ & & 2.34 & 1.42
\end{tabular}




\section{Maternal Family (n) males females monoecious}

$\chi_{1: 1}^{2}$

$12.3^{2}$

\section{Cross 5:}

오 dioica $\times$ gracilis (monoecious)

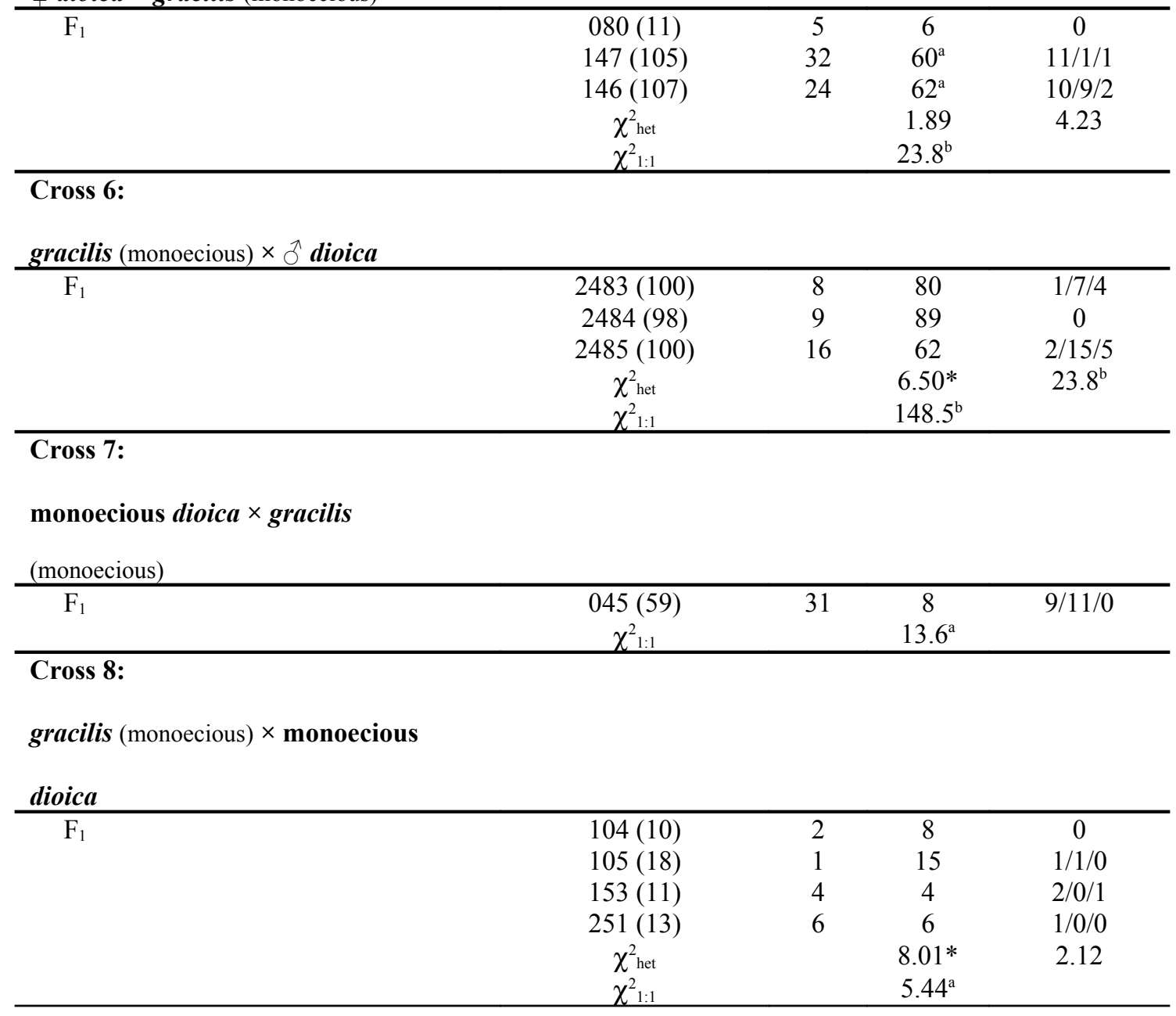

